\title{
Clean, cheap, convenient: promotion of Electronic cigarettes on YouTube
}

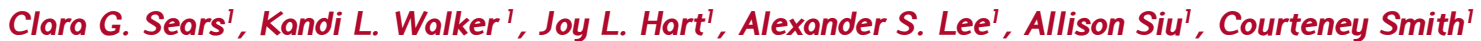

\begin{abstract}
INTRODUCTION Videos promoting electronic cigarettes (e-cigarettes) can be easily accessed on YouTube. Marketing claims present in YouTube videos may help shape the public's opinion of e-cigarettes. Thus, it is important to understand the most frequent marketing claims and video sources.

METHODS The objectives of this study were to 1) identify marketing claims in YouTube videos that are commonly made on e-cigarette retail websites and 2) compare the frequency of marketing claims in user-generated and professional YouTube videos. Through content analysis, this study evaluated six marketing claims and descriptive information about YouTube videos $(\mathrm{n}=50)$ related to "electronic cigarettes" and "vape".

RESULTS Overall, the most frequent marketing claim promoted e-cigarette use as better than traditional tobacco use $(52 \%)$. Approximately $65 \%$ of videos appeared to be user-generated and $35 \%$ were professionally-produced. Compared to user-generated videos, significantly more professional videos made claims that e-cigarettes are cleaner $(\mathrm{p}<0.001)$ and cheaper $(\mathrm{p}=$ 0.04 ) than traditional cigarettes. Additionally, more professional videos had claims promoting e-cigarettes as better than traditional cigarettes because of their convenience- the user can smoke anywhere $(\mathrm{p}<0.0001)$ and the products do not produce secondhand smoke $(\mathrm{p}<0.001)$. The most frequent claim in user-generated videos was related to recreation $(53 \%)$.

conclusions Videos on YouTube promote e-cigarettes as safer than other tobacco products. Videos appearing to be user-generated contained different marketing claims compared to professional videos. Further research is necessary to assess how the perceived source of the video

impacts the ways these marketing claims shape public perception and influence use.
\end{abstract}

\section{INTRODUCTION}

Electronic cigarette, or e-cigarette, companies use Internetbased marketing schemes to promote products in ways that appeal to youth ${ }^{1-3}$. In addition, people interested in e-cigarettes are seeking information on the World Wide Web, in particular on social media, to understand the products ${ }^{4,5}$. Due to widespread marketing and increasing sales of e-cigarettes, it is important to consider how marketing claims may shape the public's perception.

The video-sharing website, YouTube, provides over 1 billion users global access to user-generated videos, as well as professionally produced television clips, advertisements, and more. In the past, YouTube has been used to advertise other tobacco products through videos that promote brands, tobacco-company-sponsored events, and smoking fetishes ${ }^{6,}$ ${ }^{7}$. Recent studies have found that similar techniques may be utilized to promote e-cigarettes on YouTube ${ }^{3,8,9}$.

The promotion of e-cigarettes on YouTube occurs via professional videos, as well as user-generated product reviews that appear to share personal experiences with e-cigarettes ${ }^{10}$. Claims made in professional videos could differ from those made in user-generated videos, which can be influenced by subjective reactions to marketing claims from other media outlets, such as retail websites ${ }^{3}$. Additionally, viewer perception and critique of video content can be affected by the perceived source of the message ${ }^{11}$. Thus, it is important to compare 
professional and user-generated videos because marketing claims could be perceived differently. The objectives of this study are to 1) identify marketing claims in YouTube videos that are commonly made on e-cigarette retail websites and 2) compare the frequency of marketing claims in user-generated and professional YouTube videos.

\section{METHODS}

Videos related to e-cigarettes and vaping were located on YouTube using the search terms "electronic cigarette," "e-cigarette," and "vape" in spring 2014. "Vape" refers to the act of inhaling the aerosolized liquid produced by e-cigarettes. Similar to other studies evaluating e-cigarette messaging on YouTube, the search terms were selected based on their popularity ${ }^{9}$. Using Google Trends "electronic cigarette" and "vape" were found to be among the most frequently searched terms to describe the product. "E-cigarette" was searched less frequently but was included to ensure the most popular videos were captured with the other terms. The videos were sorted based on a view count and three members of the research team individually analyzed the fifty most viewed videos in English. Total view count was used to sort the videos in order to collect a sample of e-cigarette claims that reached the largest audience and therefore may have the broadest impact on public perception of e-cigarettes. Including fifty videos likely captures items that are contained in the first couple of search pages generated by YouTube. Duplicate videos that appeared for multiple search terms were only counted and reviewed once.

Content analysis of the videos was done in several steps. First, descriptive information about the video was recorded. Reviewers also documented if age verification was required, if links to retailer and social media websites were provided, and if the video was posted on a channel solely devoted to vaping. Next, general information about the content was collected. The video was coded as a professional video, defined as a video posted by a television studio, production company, or organization, or appearing to be a user-generated video, defined as a video posted by a person not clearly associated with a specific company. The overall depiction of e-cigarettes in the video was coded as positive (promoting products/use), negative (discouraging products/use), or neutral (open to viewer interpretation, e.g., a news report providing a basic definition). Reviewers also documented whether the video contained any health warnings. Finally, video content was analyzed for specific marketing claims commonly made on e-cigarette retail websites. A coding guide using categories adapted from Grana and Ling's (2014) analysis of retail websites was used to assess marketing claims in YouTube videos ${ }^{12}$. This coding guide was selected to enable comparison of our findings to the frequency of marketing claims on more obvious e-cigarette advertising platforms. Prior to coding the videos, research team members were provided detailed definitions of the marketing claims and examples were discussed.

After research team members viewed videos individually, the overall frequency of marketing claims was calculated. A marketing claim was deemed to be present in a video if at least two reviewers noted its presence. In cases where only one reviewer noted the presence of a marketing claim, the video was reviewed again and discussed until agreement was reached. SAS 9.3 (Cary, N.C.) was used to calculate descriptive characteristics. Fisher's exact p-values were calculated to compare marketing claims in user-generated and professional videos.

\section{RESULTS}

Of the fifty YouTube videos selected, forty-six were included in the study; four were excluded due to content being disabled. Two reviewers coded for marketing claims; any disagreements were discussed and the video was reexamined until agreement about the claims was reached. The videos ranged in length from 23 seconds to 18 minutes. Approximately 67\% (31) were posted on a YouTube channel primarily dedicated to videos about vaping. About $65 \%$ (30) provided a website link for purchasing e-cigarettes, and 30\% (14) provided links to other social media websites. Only 9\% (4) required age verification and health warnings were contained in approximately $15 \%$ (6). In 93\% (43), the overall depiction of e-cigarettes was positive; no videos depicted e-cigarettes negatively; 7\% (3) were neutral.

Approximately 65\% (30) were user-generated and 35\% (16) were professional videos. Overall, user-generated videos had 16,003,231 views with an average like-to-dislike ratio of 12:1. Professional videos had 10,105,452 views with an average like-to-dislike ratio of 18.5:1.

The most frequent marketing claim conveyed in the YouTube videos was that e-cigarettes are better than other tobacco products $(52 \%)$. This claim was further analyzed with subcategories (Table 1). The most frequent subcategory was the claim that e-cigarettes are cleaner than other tobacco products $(30 \%$; Table 1$)$. For example, one video claimed e-cigarettes contain "nicotine and water vapor," while also stating, "there are something like 30 different carcinogenic chemicals in [traditional] cigarettes."

The second most frequent marketing claim was related to recreation $(48 \%)$. For example, one video posed the 


\section{Research Paper}

Table 1. Marketing Claims in YouTube Videos

\begin{tabular}{|c|c|c|c|c|}
\hline $\begin{array}{l}\text { Marketing Claim } \\
\text { Definition }\end{array}$ & $\begin{array}{c}\text { Total } \\
(n-16)\end{array}$ & $\begin{array}{l}\text { User generated } \\
\qquad(\mathrm{n}-30)\end{array}$ & $\begin{array}{l}\text { Professional } \\
\qquad(n-16)\end{array}$ & p-value \\
\hline $\begin{array}{l}\text { Recreation } \\
\text { Depicts use as fun and/or social; demonstrates tricks; } \\
\text { discusses customizing options; highlights use and modifying of } \\
\text { products as a hobby. }\end{array}$ & $48 \%(22)$ & $53 \%(16)$ & $38 \%(6)$ & 0.36 \\
\hline $\begin{array}{l}\text { Technology } \\
\text { Depicts products as advanced, trendy, and/or modern; } \\
\text { contains information about the science behind the products and } \\
\text { how to build products. }\end{array}$ & $39 \%(18)$ & $37 \%(11)$ & $44 \%(7)$ & 0.75 \\
\hline $\begin{array}{l}\text { Health } \\
\text { Portrays use as providing health benefits, reducing harm, or } \\
\text { not being harmful to one's health. }\end{array}$ & $37 \%(17)$ & $23 \%(7)$ & $63 \%(10)$ & 0.01 \\
\hline $\begin{array}{l}\text { Social Status } \\
\text { Portrays e-cigarettes as more modern in appearance and } \\
\text { helping users' social image. }\end{array}$ & $13 \%(6)$ & $7 \%(2)$ & $25 \%(4)$ & 0.16 \\
\hline $\begin{array}{l}\text { Cessation Aid } \\
\text { Portrays use as able to help with tobacco cessation. }\end{array}$ & $28 \%(13)$ & $23 \%(7)$ & $38 \%(6)$ & 0.33 \\
\hline $\begin{array}{l}\text { Better than other tobacco products } \\
\text { because... }\end{array}$ & $52 \%(24)$ & $33 \%(10)$ & $88 \%(14)$ & 0.0005 \\
\hline $\begin{array}{l}\text { Cleaner } \\
\text { Have fewer chemicals, no smell, and do not stain teeth }\end{array}$ & $30 \%(14)$ & $10 \%(3)$ & $69 \%(11)$ & $<0.001$ \\
\hline $\begin{array}{l}\text { Convenient/use anywhere } \\
\text { Can be used indoors and other places where traditional } \\
\text { cigarettes are not allowed }\end{array}$ & $22 \%(10)$ & $7 \%(2)$ & $50 \%(8)$ & 0.002 \\
\hline $\begin{array}{l}\text { Cheaper } \\
\text { Long-term cost lower than traditional tobacco products }\end{array}$ & $7 \%(3)$ & $0 \%(0)$ & $19 \%(3)$ & 0.04 \\
\hline No secondhand smoke & $15 \%(7)$ & $0 \%(0)$ & $44 \%(7)$ & $<0.001$ \\
\hline
\end{tabular}

question, "Do you want to experience the vast and delicious world of e-liquids?" suggesting trying different flavors was an exploratory activity. Nearly two-thirds $(64 \% ; 14)$ of videos that contained marketing claims related to recreation did not contain claims comparing e-cigarettes to other tobacco products $(\mathrm{x} 2=4.22 ; \mathrm{df}=1 ; \mathrm{p}=0.04)$.

Although the most common claims in user-generated videos centered in recreation (53\%), the most common claim in professional videos was that e-cigarettes are better than other tobacco products $(88 \%)$, especially because they are cleaner (69\%). Marketing claims about e-cigarettes being beneficial to health ( $\mathrm{p}=0.01$ ), cleaner than other tobacco products ( $\mathrm{p}$ $<0.001)$, cheaper than other tobacco products $(\mathrm{p}=0.04)$, convenient to use $(p=0.002)$, and free of secondhand smoke $(\mathrm{p}<0.001)$ were significantly more common in professionallyproduced videos compared to user-generated videos.

\section{DISCUSSION}

Unlike other studies assessing e-cigarette messaging on YouTube $^{8,9}$, we evaluated the infiltration of e-cigarette marketing claims perpetuated by retail websites into YouTube videos. In addition, this study is novel because we compared marketing claims in videos appearing to be user-generated with claims in professionally-produced ones.

The most common marketing claim was that e-cigarettes are better than other tobacco products. These results differ from Grana and Ling's (2014) finding that the most frequent marketing claims on e-cigarette retail websites were related to health and tobacco cessation ${ }^{10}$, but are similar to other recent studies evaluating the portrayal of e-cigarettes in YouTube videos $^{3,10,12}$.

Similar to findings from Romito et al. (2015), the majority of the videos assessed appeared to be user-generated ${ }^{9}$. Our findings add to the current body of literature by suggesting that claims positively comparing e-cigarettes to other tobacco products occur more often in professional videos, whereas the most prevalent claim in user-generated videos is related to recreation. No studies have evaluated how perceptions of YouTube videos affect e-cigarette use; however, claims perpetuated by e-cigarette promotion online may help shape public acceptance of e-cigarettes ${ }^{3,10,12,13}$. Also, professional videos fared somewhat better than user-generated ones in liketo-dislike ratios, suggesting the potential for greater influence on viewers and an area for future inquiry. 
Our findings extend similar conclusions in related work: that the majority of YouTube videos promoting e-cigarettes demonstrate the social benefit and acceptability of e-cigarettes in part by claiming that using e-cigarettes is safer and healthier than consuming traditional tobacco products ${ }^{3,10}$. This comparison perpetuates a narrative that e-cigarettes are safe because they are "healthier" or "safer" than other traditional tobacco products. Promoting a product by claiming that it is better than a hazardous substance, like traditional tobacco, only has merit when targeting cigarette users who are considering quitting or cutting back ${ }^{14}$. Given that scientific information about safety is largely inconclusive, claims using words like "safer" to describe e-cigarettes could contribute to confusion about the overall safety of these products, especially among youth. A recent analysis found that $34.2 \%$ of youth believe that e-cigarettes are less harmful than traditional cigarettes, and $45 \%$ are not sure ${ }^{13}$. Furthermore, e-cigarette use among youth who did not use traditional cigarettes was more likely when they perceived e-cigarettes to be less harmful than traditional cigarettes ${ }^{13}$. The perceived safety of e-cigarettes may also be a contributing factor in the increasing trend of e-cigarette use among adult never and former smokers ${ }^{15}$. Future research is necessary to assess the implications of claims promoting e-cigarettes as better than traditional cigarettes on audience perception and use.

The majority of videos containing recreation-related claims were user-generated and did not compare e-cigarettes to other tobacco products. This finding is important because viewers may be less critical of information presented by other consumers compared to information that appears to be presented by a specific manufacturer or retailer ${ }^{9}{ }^{11}$. Additionally, a majority of videos promoting e-cigarettes with recreational marketing claims use web links to connect viewers to retail stores, allowing youth to purchase products online and circumvent barriers to obtaining e-cigarettes. Thus, user-generated videos may be more likely to directly connect youth consumers to products. Assessing the believability, authenticity, and persuasiveness of user-generated videos, and especially their effects on youth, would be valuable in future research. None of the videos analyzed in this study were found to negatively portray e-cigarettes. Likewise in the samples analyzed by Paek et al. (2014), Luo et al. (2014), and Romito et al. (2015) $6 \%$ or fewer of the videos were found to be "anti" e-cigarette ${ }^{3,9,10}$. There is a need for "anti" e-cigarette videos on YouTube, especially ones targeted at youth, to more accurately convey current scientific understanding about the safety of these products and to combat marketing claims related to recreation. Areas for future research include examining how safety, health, and recreational claims shape viewer attitudes, beliefs, and behavior as well as social norms.

Some limitations need to be considered. First, a relatively small sample of videos was assessed. By selecting the most viewed, however, we analyzed the videos with the greatest potential to influence public perceptions. Second, misclassification or bias could result during the identification of marketing claims. In order to reduce bias and maintain consistency in coding, the reviewers were provided with a detailed definition of the marketing claims and multiple researchers viewed each video.

In conclusion, the most frequent marketing claim in YouTube videos promotes e-cigarettes as better than other tobacco products. Such claims were found to occur more often in professional videos than ones appearing to be usergenerated. It is important to further assess how the perceived video source impacts viewer perception of marketing claims and the overall influence on the public's perception and use of e-cigarettes.

\section{REFERENCES}

1 de Andrade M, Hastings G, Angus K: Promotion of electronic cigarettes: tobacco marketing reinvented?. BMJ [2013], 347:f7473. doi: 10.1136/bmj.f7473.

2 Yamin CK, Bitton A, Bates DW: E-cigarettes: a rapidly growing internet phenomenon. Ann Intern Med [2010], 153:607-9. doi: 10.7326/0003-4819-153-9-201011020-00011.

3 Paek HJ, Kim S, Hove T, Huh JY: Reduced harm or another gateway to smoking? source, message, and information characteristics of e-cigarette videos on YouTube. J Health Commun [2014], 19(5):545-60. doi: 10.1080/10810730.2013.821560.

4 Noel JK, Rees VW, Connolly GN: Electronic cigarettes: a new 'tobacco' industry? Tob Control [2010], 20:81. doi: 10.1136/tc.200.0138562.

5 McQueen A, Tower S, Sumner W: Interviews with «vapers»: implications for future research with electronic cigarettes. Nicotine Tob Res [2011], 13(9):860-7.

doi:10.1093/ntr/ntr088.

6 Elkin L, Thomson G, Wilson N: Connecting world youth with tobacco brands: YouTube and the internet policy vacuum on Web 2.0. Tob Control [2010], 19(5):361-6.

doi: 10.1136/tc.2010.035949.

7 Freeman B, Chapman S: Is «YouTube» telling or selling you something? tobacco content on the YouTube video-sharing website. Tob Control [2007], 16(3):207-10. doi:10.1136/tc.2007.020024.

8 Huang J, Kornfield R, Emery SL: 100 million views of electronic cigarette YouTube videos and counting: quantification, content evaluation, and engagement levels of videos. J Med Internet Res [2016], 18(3):e67. doi: $10.2196 /$ jmir. 4265 .

9 Romito LM, Hurwich RA, Eckert GJ: A snapshot of the depiction of electronic cigarettes in YouTube videos. Am J Health Behav [2015], 39(6):823-31. 


\section{Research Paper}

doi: 10.5993/AJHB.39.6.10.

10 Luo, C, Zheng X, Zeng DD, Leischow S: Portrayal of electronic cigarettes on YouTube. BMC Public Health [2014], 14:1028. doi: 10.1186/1471-2458-14-1028.

11 Steyn, P, Ewing MT, van Heerden G, Pitt LF: From whence it came: understanding source effects in consumer-generated advertising. International J Advertising [2011], 30(1):133.

doi: 10.2501/ija-30-1-133-160.

12 Grana RA, Ling PM: «Smoking revolution»: a content analysis of electronic cigarette retail websites. Am J Prev Med [2014], 46(4):395-403.

doi: 10.1016/j.amepre.2013.12.010.

13 Amrock SM, Zakhar J, Zhou S, Weitzman M: Perception of e-cigarette harm and its correlation with use among U.S. adolescents. Nicotine Tob Res [2015], 17(3):330-6.

doi: $10.1093 / \mathrm{ntr} / \mathrm{ntu} 156$.

14 Schraufnagel DE: Electronic cigarettes: vulnerability of youth. Pediatr Allergy Immunol Pulmonol [2015], 28(1):2-6. doi: 10.1089/ped.2015.0490.

15 McMillen RC, Gottlieb MA, Shaefer RM, Winickoff JP, Klein JD: Trends in electronic cigarette use among U.S. adults: use is increasing in both smokers and nonsmokers.

Nicotine Tob Res [2015], 17(10):1195-202.

doi: $10.1093 /$ ntr/ntu213.

CONFLICT OF INTERESTS

The authors have

completed and submitted the ICMJE Form for

Disclosure of Potential Conflicts of Interest and none were reported.

\section{FUNDING}

This work was supported, in part, by the National Heart, Lung and Blood Institute (NHLBI) and FDA Center for Tobacco Products (CTP) (grant number 5P5OHL120163). The project also received support from the Department of Communication at the University of Louisville. FDA funding pertained only to aspects of the project that were under CTPFDA regulatory authority at the time of the data collection. The content is solely the responsibility of the authors and does not necessarily represent the official views of the $\mathrm{NIH}$ or the Food and Drug Administration.

PROVENANCE AND PEER REVIEW

Not commissioned;

Externally peer reviewed 